\title{
EDITORIAL
}

\section{LA ASAMBLEA LEGISLATIVA SON DOS}

$\mathrm{U}$ na de las virtudes en que fallamos los salvadoreños es la puntualidad que, con frecuencia se convierte en una gran falta de respeto a sí mismo y a los demás. Hasta hacemos gala de "la hora salvadoreña". El inicio del Foro de Concertación Económica y Social (FES) se retrasó unos tres meses, y ya que fueron lentos en comenzar han sido más prestos en clausurar. El calendario de los Acuerdos de Paz se ha reacomodado en la mayoría de sus items, con el riesgo de que la falta de puntualidad se convierta en falta de memoria de las claúsulas pactadas. Tampoco el Tribunal Supremo Electoral se distinguió por supuntualidad, lo que dió lugar a que estuvieran presentes bastantes difuntos y ausentes muchos vivos. En los meses de junio-julio le tocó el turno a la nueva Asamblea Legislativa y a la estatua de la Justicia que por más de quince días ha estado en espera del humo blanco. Esta falta de puntualidad, sea constitucional o anticonstitucional, es algo muy grave.

La elección de la Corte Suprema de Justicia fué preparada con la adecuada antelación. Hace más de dos meses que el gremio de abogados votó masiva y conscientemente por los mejores candidatos que, a su autorizado juicio, serían idóneos magistrados en la cúspide del Organo Judicial. Lo hicieron conscientes de que no puede haber Estado de Derecho sin práctica de la justicia. El Consejo Nacional de la Judicatura complementó puntualmente el listado y la nueva Asamblea Legislativa disponía a tiempo de los mejores insumos para integrar la Corte Suprema. En este caso, tan 
importänte es considerar los efectos como las causas de tan grave impuntualidad. No se tardaron los juristas en alertamos sobre los efectos en el proceso de administración de justicia. "Gremio de abogados señala ilegalidades y urge Corte."( El Diario de Hoy.8julio-94;p.3). Ahora queremos indagar más bien las causas de tan serio irrespeto.

Todo comenzó cuando el partido de la imposición y los suyos vetaron cinco nombres a los escaños de esta magistratura. Tal vez vetaron a cinco para disimular la intención de vetar a uno. Inicialmente se dijo que no podian exteriorizar las razones para salvaguardar la reputación de estos profesionales. A juzgar por declaraciones posteriores, no creemos que ARENA tenga verdaderas razones para el veto, porque las razones emanan de la razón y son afirmaciones razonadas. Después buscaron un título colorado: el candidato de la oposición para la Corte Suprema ha tenido una notoria militancia partidista pues en su día buscó ser candidato presidencial. Sin embargo no es éste el verdadero motivo, porque ello significaría que cualquiera de los recientes o pasados candidatos presidenciales quedarian -ipso facto- descalificados para el ejercicio de la Suprema Corte de Justicia, al igual que el resto de líderes políticos. No es ésta ni la cualidad ni el impedimento para ingresar en la cúspide el Organo Judicial.

Lo que realmente ocurre es que el partido de la imposición no acepta ninguna oposición en cualquiera de los poderes públicos . No acepta la oposición, ni la independencia en la Corte Suprema de Justicia porque teme que se haga arqueología histórica del pasado (incluído su fundador) y peligre así su historia futura. Los pronunciamientos, juicios y contrajuicios de valor, trasladados a nuestros diarios confirman esta apreciación. Si el gremio de abogados ponderó sensatamente las cualidades de sus candidatos , sin duda quienes han procurado iluminar hasta la última hora constitucional la mente y las voluntades de nuestros diputados ha sido un grupo selecto de veteranos juristas, ex-ministros y ex-presidentes de instituciones públicas, ajenos a toda sospecha opositora por ser los doce firmantes reconocidos hombres del derecho, e incluso de la derecha.

Con fecha 29 de junio (El Diario de Hoy; p.18) lanzaron un salvavidas a los entrampados curules. El texto merece una pausa y una 
aclaración. No lo trasladamos porque elogia a una persona concreta, a quien mucho estimamos, sino porque representa un símbolo de lo que requiere nuestra Corte Suprema, sus funciones constitucionales y las expectativas ciudadanas:

"Con todo respeto nos dirigimos a ese importante Organo de Estado, para hacerle llegar nuestros puntos de vista, con relación al nombramiento del Presidente de la Corte Suprema de Justicia que se ha de llevar a cabo en los próximos días. Para llegar a la decisión sobre quién debe ser el futuro Presidente de la Corte Suprema de Justicia, deben tomarse en consideración determinadas circunstancias, que entre otras señalamos las siguientes:

1) El candidato debe ser un jurista reconocido con larga trayectoria en el campo del hacer juridico.

2) Debe caracterizarse como un funcionario serio, firme, valiente y dispuesto a afrontar las dificultades que ocurran en el desarrollo de su cargo y convertirse en un Director probo y digno en el manejo de los asuntos oficiales en que debe intervenir.

3) Antes que otra consideración, el Presidente del Organo Judicial debe ceñirse en sus funciones a la defensa firme del orden juridico, en el sentido de que la ley y el derecho imperen en el campo judicial.

4) El Presidente de la Corte debe traslucir la imagen de un personaje alejado de los vaivenes políticos de ocasión o de los entendimientos que se suscitan entre particulares y/o grupos políticos, o de idelogias de esta indole.

Aceptadas las condiciones anteriores, queremos hacer llegar a los señores Diputados nuestras conclusiones sobre la persona que consideramos más adecuada para llenar este importante cargo en los momentos actuales por los que atraviesa el pais.

La persona que estimamos que podría ser el nuevo Presidente de la Corte Suprema de Justicia es el Dr. Abraham Rodriguez, quien entre sus cualidades personales ostenta las siguientes..." (En razón de la brevedad recortamos el largo panegirico, intercalando algunos méritos que debilitan la posición de ARENA )..." Su participación politica ha sido en bien del pais, alejado de todo partidismo antipatriótico y con una transparencia tal en el ejercicio de sus funciones que no puede reprochársele algo incorrecto. Cuando el Secretario General de las Naciones Unidas y el Presidente Cristiani solicitaron su colaboración para participar en una de las Comisiones creadas en los Acuerdos de Paz, de enorme transcendencia para la vida institucional del pals, el Dr. Abraham Rodriguez aceptó formar parte de la Comisión Ad-Hoc...El Dr. Rodriguez servirfa al Gobiemo de la República como un intermediario, apolítico e imparcial, con la oposición gubemamental que también le brinda su apoyo, evitando asl confrontaciones innecesarias.

Por último, señores diputados, a nadie escapa la importancia transcendental que tiene para la sociedad salvadoreña la seguridad de tener una honesta,capaz y pronta administración de justicia, columna vertebral de un Estado de 
Derecho...Queremos recalcar que nuestra posición no representa confrontación alguna con los otros candidatos posibles para ocupar tan distinguido cargo, ni un demérito a sus personalidades"...

Cuando leímos esta autorizada declaración pensamos que para el primero de julio estaría nominada la Corte Suprema de Justicia. El último párrafo citado, que no es el último del pronunciamiento de nuestros veteranos juristas, es importante para la interpretación del presente debate. Se dice claramente que no existe ese único candidato, que otras personalidades, con lo que encierra esta expresión , serían competentes para dicha presidencia. Seria de esperar, por lo tanto, que ARENA sacara de su baraja otros cuatro o cinco panegíricos dignos de similar consideración. Como dice el refrán: por su boca muere el pez. Han sido los ataques a este candidato de la oposición los que nos llevan a deducir las causas un tanto turbias de su oposición.

Nos acercamos a mediados de julio y los diarios nos siguen listando las razones y las sinrazones, de acuerdo a cada caso, de los diputados litigantes. Los periódicos matutinos recogen en sugestivos recuadros los tiras sin afloja que mantienen el impasse: "Las trabas de la elección”. "¿Oposición quiere el tercer poder."( El Diario de Hoy; 7 y 8 julio-94) Junto a los recuadros, una foto del Dr. Abraham Rodríguez con los miembros de la Comisión Ad-Hoc. ARENA LE SACA LA TARJETA ROJA. Ese candidato es partidista; forma parte de la Comisión Ad-Hoc, que también es partidista. La traducción no es inventada; aparece en los citados recuadros.

¿Por qué no Abraham Rodriguez ?..." Su participación activa en la Comisión Ad-Hoc, que determinó el unilateral enjuiciamiento moral de miembros de la Fuerza Armada y el posterior retiro de estos de sus cargos, vuelven a Rodríguez sospechoso de parcialismo, lo cual es inadmisible para un magistrado"...Irónica conclusión, si literalmente la expetó algun diputado. Se constituye bilateralmente una Comisión Ad-Hoc (= para esto), investigar miembros de las fuerzas armadas implicados en actos violatorios de la justicia, y el error del Dr.Abraham Rodriguez y comisionados fué no haber entregado cien páginas en blanco, de acuerdo a la práctica del "se harán investigaciones exhaustivas". Consejo ilustrativo-para los próximos magistrados: investiguen pero no enjuicien moralmente para no pecar de unilateralismo. Con estos 
silogismos, a quiénes están protegiendo ARENA y los suyos ?: Sin embargo, la lucha no es por una persona, sino por una institución, aunque las dos cosas van de la mano. Volviendo a nuestros recuadros que, en nota de pie de página, dicen recoger el crịterio de diputados de ARENA y analistas políticos del pais, se pregunta "Qué pasaría si la izquierda se apodera de la Corte?" - Las respuestas develan los verdaderos motivos del veto: "l) Si es elegido su candidato, Abraham Rodríguez, éste pavimentaria, desde la Corte, su propia ruta hacia la Casa Presidencial, en los próximos comicios de 1999. 2) El bloque opositor estaria en condiciones de presionar sobre la gestión del gobierno ARENA, obligando a éste a entrar en negociaciones. 3) El país correría el riesgo de ser ingobernable, a menos que se acepten las condiciones de la izquierda. 4) La ingobernabilidad y la politización de las gestiones del Organo Judicial generarian incertidumbre jurídica, lo cual incide a su vez en los órdenes político, laboral y sobre todo en los económico." ( El Diario de Hoy; 7 de julio-94;p.5). Estas declaraciones dicen más de lo que dicen. De acuerdo a la nota al pie de página , estas opiniones pueden emanar de analistas políticos, aunque los diputados de ARENA las guardan en su corazón. Sean quienes sean los autores merecen una breve reflexión.

Estos testimonios más que implicitamente enuncian la tesis de que el buen gobierno requiere no tener oposición en ninguno de los poderes públicos. Pero precisamente éste ha sido uno de los rasgos más criticados en los "socialismos reales" del Este europeo, donde también gobernaban sus derechas. Deduciríamos una tesis bastante universal: las derechas del Este y del Oeste deben evitar la oposición para sostener un buen gobierno. Esta fué la violencia estructural que ha delatado ei informe de la Comisión de la Verdad:" las alianzas oportunistas "de los poderes públicos que fundamentaron la tesis de que también las instituciones delinquen.

Lo más triste de semejantes declaraciones es que literalmente transforman la gobernabilidad en ingobernabilidad. Anulan el sentido de las elecciones nacionales si en todo tiempo, lugar y poder hay que escoger a los mismos para que haya gobernabilidad; tendríamos la gobernabilidad de cuartel. Todos los poderes serían, al unísono, juez y parte y sólo nos quedaría el resquicio de acudir a las Naciones Unidas, como en Haití. Recordemos cómo y por qué 
nacieron los Acuerdos de Paz. Los que acusan de posición partidista profesan el más restringido partidismo al querer acaparar todos los poderes públicos y privados, integrando la concentración económica. El equilibrio político necesita poderes compensadores, precisamente," para que haya credibilidad y no incertidumbre en los órdenes jurídico, político y sobre todo en lo económico". Se dice - de palabra - no a los monopolios económicos, pero se quieren acaparar todos los poderes públicos, que también bendecirán la concentración económica. Si no reconocemos que en todos estos órdenes hay serios conflictos entre el poder y la justicia de muy poco han servido los Acuerdos de Paz.

Han sido las declaraciones vertidas en los medios de comunicación las que nos llevan a interpretar las causas del impasse en la Asamblea Legislativa, donde suena más la música del poder centralizador que el servicio de la justicia, esperada como el Mesías. Sólo nos queda dejar a reflexión de nuestros diputados aquel sabio principio con que nuestros veteranos juristas cierran el citado pronunciamiento. "Cuando el ciudadano pierde la confianza en los jueces, puede decirse que ya casi se ha perdido todo, pues los derechos que una recta administración de justicia debería tutelar quedan al garete; se pierde la credibilidad, se afecta la seguridad en las relaciones humanas y se vuelve cosa muerta la vida del Derecho. En tales circunstancias las naciones que sufren esos males sucumbirán también por la conducta de sus propios juzgadores". 